\title{
The effectiveness of propolis on the healing period of recurrent aphthous stomatitis
}

\author{
Foo You Han*, Riani Setiadhi*, Indrati** \\ *Department of Oral Medicine Faculty of Dentistry Universitas Padjadjaran \\ **Department of Oral Biology Faculty of Dentistry Universitas Padjadjaran
}

\section{ABSTRACT}

Introduction: Propolis ${ }^{\circledR}$, also known as bee glue, is a substance acquired from the bee hive, which contain antimicrobial, antiviral and antifungal properties. The aim of this research was to identify the best concentration of propolis ${ }^{\circledR}$ that is effective for healing period of Recurrent Aphthous Stomatitis (RAS). Methods: This research was experimental study and the sample are patients who have Recurrent Aphthous Stomatitis during the extent of the research at Rumah Sakit Gigi dan Mulut, Bandung, Indonesia. the patients were given Propolis $®$ of either $0.5 \%$ or $1.0 \%$ concentration randomly. Results: Using the Kolmogorov-Smirnov test, the data is tested for normality of patients whom are applying Propolis $®$ cream at concentration of $0.5 \%$ and $1 \%$. The average time taken for the subject with $0.5 \%$ Propolis $®$ cream to fully heal were 5 days, while those with $1.0 \%$ Propolis ${ }^{\circledR}$ cream required 6 days. From the t-test for equality of means, where $0.140>0.05$, we can conclude that the difference is not significant between subjects that were given Propolis ${ }^{\circledR}$ cream at $0.5 \%$ concentration compared with subject given with $1.0 \%$ concentration of Propolis $₫$ cream. The result shows that Propolis at $0.5 \%$ concentration provides an average healing period of 5 days while propolis at $1.0 \%$ on an average of 6 days for the healing of RAS. Conclusion: Propolis at $0.5 \%$ is more effective compared to $1.0 \%$ for healing period of Recurrent Aphthous Stomatitis.

Keywords: Propolis, healing period, recurrent aphtous stomatitis.

\section{INTRODUCTION}

The usage of natural product as a means for health and recovery has been getting more popular. This is because natural products contain more benefits than commercial medications and nutritional supplements that we take on daily basis. As for Propolis $₫$, while having very prominent benefits, it is still bee product hence its only downside is that it will not be suitable for people with bee allergies.
Propolis $₫$, also known as bee glue, is a substance acquired from the bee hive. The bees obtain Propolis $®$ from the resins of the bark of trees, fruits and leaves. The resins are used by bees as an adhesive to form the beehive and reinforce its stability, making the hive more defensible by sealing alternate entrance, as well as to prevent diseases and parasite from entering the hive to inhibit bacterial growth. ${ }^{1}$ However, it is still unclear which species of the plants and what cues are used by the honey bees to find resins. ${ }^{1}$ 
What once thought to be of no use in medication, Propolis $₫$ turns out to be a valuable essential oil that helps aid the body to fight disease and to provide better living standards for our lives. It contains antimicrobial, antiviral and antifungal properties that can help protect our bodies from pathogens and harmful microbes. ${ }^{2}$ The duration of Recurrent Aphthous Stomatitis (RAS) before and after the treatment with Propolis ${ }^{\circledR}$ was also shortened. The number of patients with ulcer duration of five days or less increased after applying Propolis ${ }^{\circledR}$ treatment, a significant improvement compared to having to experience ulcer duration for 6-20 days before Propolis ${ }^{\circledR}$ treatment was proposed. ${ }^{3}$ If the numbers of RAS during each recurring period before and after treatment are to be compared, the Propolis ${ }^{\circledR}$ solution appears to have induced a reduction in the mean number of ulcers that developed. Patients who previously had 4-6 ulcers per episode, instead had 1-3 ulcers after Propolis $₫$ treatment. $^{3}$

In the research by Samet, it is said that Propolis ${ }^{\circledR}$ may confer some advantages in the treatment and management of patients with Recurrent Aphthous Stomatitis (RAS), suggesting that patients taking Propolis ${ }^{\circledR}$ are more likely to achieve reductions in number of Recurrent Aphthous Stomatitis (RAS), compared to those patients on placebo. Their study has also shown that Propolis ${ }^{\circledR}$ is effective in decreasing the number of recurrences and improve the quality of life in patients who suffer from Recurrent Aphthous Stomatitis (RAS). ${ }^{4}$

Research made by Holcova has reported that the overall results of this study point to a concentration of $0.5 \%$ of Propolis $®$ extract in the lip balm as the preparation with the best risk-benefit ratio for curing Herpes Labialis. Healing periods were shorter than with the $0.1 \%$ preparation, which was expected, but also significantly shorter than with $1 \%$ Propolis $®$ extract, which was not expected, and is yet unexplained. As a hypothesis, the better effect of the $0.5 \%$ concentration might be related to subclinical tolerability. ${ }^{5}$

One difficulty in performing a study such as this one is that the research is essentially "backward" from the normal design. Since the cause of RAS is unknown, one cannot begin with a pathology or etiology to treat and can therefore only speculate on the effects of Propolis ${ }^{\circledR}$.
However, given the broad biological composition of the substance, many theories are possible. If infectious agents are considered as the cause of minor forms of RAS, then the antibacterial, antifungal, and antiviral activity of Propolis $₫$ may be the therapeutic mechanism. If the immune or inflammatory factors are etiologic, the various compounds such as flavonoids in Propolis $®$ may target these pathways. ${ }^{4}$

Based on previous research, the effect of difference in concentration of Propolis ${ }^{\circledR}$ is used to determine the effectiveness of the healing period of Recurrent Aphthous Stomatitis (RAS). Oral Medicine Department of Rumah Sakit Gigi \& Mulut was chosen as the location, as it has an abundant of patients who suffer from RAS. The aim of this research is to identify the best concentration of Propolis $₫$ that is effective for the healing period of Recurrent Aphthous Stomatitis (RAS).

\section{METHODS}

This experimental research was done using Propolis $®$ cream as a treatment for patients with Recurrent Aphthous Stomatitis (RAS) to find out the best concentration of Propolis $\AA^{\circledR}$ that will result in shorter healing period. The population is patients suffering from Recurrent Aphthous Stomatitis (RAS), and the samples are patients who have Recurrent Aphthous Stomatitis (RAS) during the time of this research at Rumah Sakit Gigi dan Mulut, Bandung, Indonesia. The inclusion criteria are patients who at the time, experienced RAS of minor case, which usually takes between 7-10 days to heal completely. The exclusion criteria include allergies towards bee products and systemic diseases such as HIV, Cancer, Pulmonary Disorders, etc. In this research, the materials used are Propolis $®(0.5 \%)$, taking form of topical cream, and Propolis $₫(1.0 \%)$, that is also taking form of topical cream. Ethical clearance has been acquired from Health Research Ethics Committee, Universitas Padjadjaran Faculty of Medical No.137/UN6.C2.1.2/KEPK/2012.

\section{RESULTS}

The period of time for the patients to fully heal from Recurrent Aphthous Stomatitis (RAS) was recorded. The healing period of RAS in accordance 
with the concentration level of Propolis of the cream will be shown on Table 1 .

In this research, the relationship between the two variables (concentration of Propolis at $0.5 \%$ and $1.0 \%$ ) and the result (The healing period of Recurrent Aphthous Stomatitis) is explored further. Using the Kolmogorov-Smirnov test, the data is tested for normality for patients whom are applying Propolis ${ }^{\circledR}$ cream at concentration of $0.5 \%$ and $1 \%$ (Table 2).

Based on Table 2, the significance value (Sig Asymp. (2-tailed)) for subjects that were given Propolis $₫$ cream at $0.5 \%$ is at 0.335 , while for subjects with $1.0 \%$ Propolis $₫$ cream is at 0.157 . Both the values are greater than 0.05 , hence we can conclude that both the data and the independent variables are normally distributed to meet the assumptions of normality.

Based on the output from above Table 3 and 4 , both the variance samples possess homogeneous data and normal distribution with significance value (sig.), concluded from t-test for equality of means, where $0.140>0.05$. Henceforth, we can conclude that the difference is not significant between subjects that were given Propolis $₫$ cream at $0.5 \%$ concentration compared with subject given with $1.0 \%$ concentration of Propolis $®$ cream. The mean time taken for the subject with $0.5 \%$ Propolis ${ }^{\circledR}$ cream to fully heal was 5 days, while those with $1.0 \%$ Propolis $®$ cream required 6 days. From the above descriptive result, we know that Propolis cream with $0.5 \%$ concentration is more effective compared to Propolis cream at $1.0 \%$ concentration. However, the results do not differ significantly, thus we can conclude that both concentrations are about the same.

Table 5 shows that the Propolis $®$ concentration of $1 \%$ had 2 subjects who had complications on day 1 . On the fourth day of recovery, two of them were healed. On the fifth day of recovery, seven of them were healed.
On the sixth day of recovery, two of them were healed. On the seventh day of recovery, three of them were healed and by the eight day, two of them were healed. The results of the statistical

Table 1. The Days Required for Subjects to Totally Heal from Recurrent Aphthous Stomatitis.

\begin{tabular}{ccl}
\hline \multirow{2}{*}{$\begin{array}{l}\text { Days Subject Take to Fully } \\
\text { Heal From RAS (Days) }\end{array}$} & \multicolumn{2}{l}{$\begin{array}{l}\text { Propolis }{ }^{\circledR} \\
\text { (Concentration) }\end{array}$} \\
\cline { 2 - 3 } & $0.5 \%$ & $\mathbf{1 \%}$ \\
\hline 4 & 5 & 2 \\
5 & 6 & 7 \\
6 & 3 & 2 \\
7 & 2 & 3 \\
8 & 0 & 2 \\
\hline Total Number of Subjects 32 & 16 & 16 \\
\hline
\end{tabular}

Table 2. Kolmogorov-Smirnov Test

\begin{tabular}{llll}
\hline & & \multicolumn{1}{c}{$\begin{array}{l}\text { Propolis } \AA \\
\mathbf{N}\end{array}$} & $\begin{array}{l}\text { Propolis } \AA \\
1.0 \%\end{array}$ \\
\cline { 3 - 4 } & & 16 & 16 \\
\hline $\begin{array}{l}\text { Normal } \\
\text { Parameters }\end{array}$ & Mean & 5.1250 & 5.7500 \\
& $\begin{array}{l}\text { Std. } \\
\text { Deviation }\end{array}$ & 5.1250 & 1.29099 \\
Most & Absolute & 1.02470 & .282 \\
$\begin{array}{l}\text { Extreme } \\
\text { Differences }\end{array}$ & Positive & .236 & .282 \\
& Negative & -.139 & -.156 \\
Kolmogorov- & & .944 & 1.127 \\
$\begin{array}{l}\text { Smirnov Z } \\
\text { Asymp. Sig. }\end{array}$ & & & \\
(2-tailed) & & .335 & .157 \\
\hline
\end{tabular}

Table 3. group Statistics

\begin{tabular}{cccccc}
\hline & $\begin{array}{l}\text { Percent } \\
(\%)\end{array}$ & N & Mean & $\begin{array}{l}\text { Std. } \\
\text { Deviation }\end{array}$ & $\begin{array}{l}\text { STD. Error } \\
\text { Mean }\end{array}$ \\
\hline Propolis & $0.5 \%$ & 16 & 5 & 1,025 &, 256 \\
& $1.0 \%$ & 16 & 6 & 1,291 &, 323 \\
\hline
\end{tabular}

Table 4 Independent Sample Test

\begin{tabular}{lllllll}
\hline & & \multicolumn{2}{l}{$\begin{array}{l}\text { Levene's Test for } \\
\text { Equality of Variances }\end{array}$} & \multicolumn{2}{l}{$\begin{array}{l}\text { t-test for Equality } \\
\text { of Means }\end{array}$} \\
\hline & & F & Sig. & T & Df & $\begin{array}{l}\text { Sig.(2 } \\
\text { tailed) }\end{array}$ \\
\hline \multirow{2}{*}{ Propolis } & Equal variance assumed & 1.847 & .184 & -1.517 & 30 & .140 \\
& Equal variance not assumed & & & -1.517 & 28.530 & .140 \\
\hline
\end{tabular}


Table 5. Comparison of Success Rate At $1 \%$ concentration

\begin{tabular}{ccccc}
\hline Propolis $®$ & \multicolumn{2}{c}{ Success Rate } & \multicolumn{2}{c}{ Significance } \\
\hline $1 \%$ & Failed/ Complication & Success/ Healed & ${ }^{2}$ & $\mathrm{P}$ \\
\hline 1 days & 2 & 0 & 18.000 & 0.003 \\
4 days & 0 & 2 & & \\
5 days & 0 & 7 & & \\
6 days & 0 & 2 & & \\
7 days & 0 & 3 & & \\
8 days & 0 & 2 & & \\
\hline
\end{tabular}

Table 6. Comparison of the propolis concentration of $1 \%$ and $0.5 \%$

\begin{tabular}{ccccccccc}
\hline Propolis $®$ & \multicolumn{4}{c}{ Propolis ${ }^{\circledR}$ Concentration 1\% } & \multicolumn{2}{c}{ Significance } \\
\hline Concentration 0.5\% & 4 Days & 5 Days & 6 Days & 7 Days & 8 Days & $\mathrm{x}^{2}$ & $\mathrm{P}$ \\
\hline 4 days & 0 & 2 & 1 & 1 & 1 & 10.730 & 0.552 \\
5 days & 1 & 4 & 0 & 0 & 1 & & \\
6 days & 0 & 1 & 1 & 1 & 0 & & \\
7 days & 1 & 0 & 0 & 1 & 0 & & \\
\hline
\end{tabular}

calculations suggested that there was a significant difference between the success rates at a concentration of $1 \%$. This has been proven by the results of the test statistic $p$ value of 0.003 .

Table 6 shows that at concentrations of $0.5 \%$ Propolis $\otimes$ with recovery period of 4 days, two of them have a 5 -day recovery with concentration of $1 \%$, each of which has a recovery of 6,7 and 8 days with a concentration of $1 \%$. Concentration of $0.5 \%$ with recovery of 5 days, 1 of whom had a recovery of 4 days with a concentration of $1 \%, 4$ of them have a 5 -day recovery at a concentration of $1 \%$ and 1 of them has a recovery 8 days with a concentration of $1 \%$. Concentration of $0.5 \%$ with the recovery of 6 days, 1 each of which has a recovery 5, 6 and 7 days with a concentration of $1 \%$. Concentration of $0.5 \%$ had recovery of 7 days, 1 each of which had a recovery of 4 days and 7 days with a concentration of $1 \%$. The results of the statistical calculations stated that there is no significant difference between the Propolis $\AA$ concentration of $1 \%$ with a concentration of $0.5 \%$. his is evidenced by the results of the test statistic $\mathrm{p}$ value of 0.552 .

\section{DISCUSSION}

The aim of this study was to provide data showing whether Propolis ${ }^{\circledR}$ at concentration of either $0.5 \%$ or $1.0 \%$ will be more effective in the healing period of Recurrent Aphthous Stomatitis (RAS). Correspondingly, the primary statistical parameter used for the assessment was not the effect on the symptoms of Recurrent Aphthous Stomatitis (RAS), but the amount of time needed for RAS to heal. This parameter allows an exact comparison of different treatments, and thus provides an answer to which concentration of Propolis $₫$ should be used in future research.

Despite the lack of a control group (placebo), the study still provides information which produces a clinically important efficacy conclusion. The impact on healing period is clearly of importance: The natural healing period of Recurrent Aphthous Stomatitis (RAS) to painless lesions that would take more than 1 to 2 weeks, can be reduced to approximately 7 days with the application of topical prednisone. ${ }^{6}$ The application of a topical cream with Propolis extract leads to a similar shortening of healing period of RAS ( 5 days with $0.5 \%$ of extract in the preparation). Propolis $₫$ is therefore confirmed to be a potent anti-ulcerous agent under clinical conditions. Propolis $₫$ cream was effective against Recurrent Aphthous Stomatitis in the 2 tested concentrations, $0.5 \%$ and $1 \%$.

This study began with a treatment that was hypothesized to treat RAS and, hopefully in the future, can elucidate the mechanism of action. Recurrent Aphthous Stomatitis (RAS) manifests 


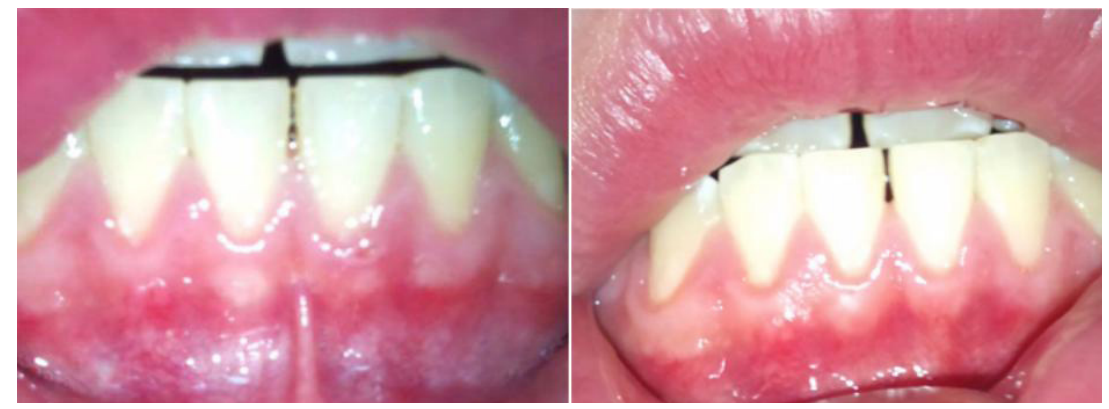

Figure 1. Patient Applied Propolis $₫$ Cream at $0.5 \%$. He Required 5 days to Fully Recover from RAS. Left: Before Treatment. Right: After Treatment

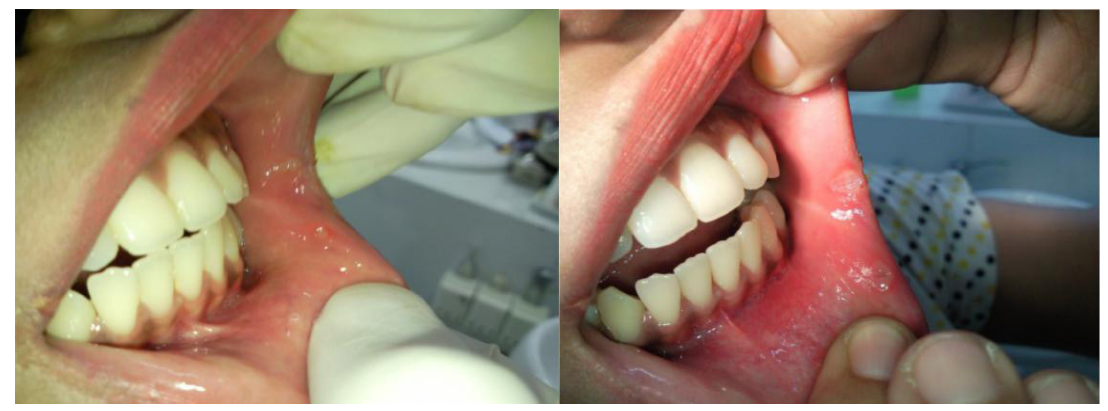

Figure 2. Patient with increased severity of RAS. She was given a Propolis $₫$ cream at $1.0 \%$ concentration. Left: Before treatment, ulcer with a diameter of $5 \mathrm{~mm}$. Right: After treatment, the ulcer increased in diameter to $10 \mathrm{~mm}$.

in varying ways in patients who suffer from the disease. As of now, there is no known etiology for the ulcers nor there is a treatment that can safely and conclusively decrease the frequency of ulcer outbreaks in a patient.

Present study shows that daily use of Propolis $\circledast$ may heal Recurrent Aphthous Stomatitis (RAS) in patients. There is no gold standard for treatment and prevention of RAS, therefore, when talking about educational aspect, there is no standard measurement to compare for emerging potential treatment. Treatment of migraine headaches has similarity in theory to treatment of RAS; patients could either treat symptoms or take medication for prevention. ${ }^{4}$

The overall results of this study point to the fact that Propolis $₫$ cream with $0.5 \%$ concentration is the best risk-benefit ratio. Healing periods of $0.5 \%$ Propolis ${ }^{\circledR}$ ( 5 days), were expectedly shorter compared with $1.0 \%$ preparation (6 days). As a hypothesis, the better effect of the $0.5 \%$ concentration might be related to subclinical tolerability. Holcová observed an increased rate of skin irritation with $2 \%$ concentration of Propolis $\otimes$ compared to $1 \%$ concentration, which still results in increased rate of irritation that is undistinguishable from the symptoms of Herpes Labialis. ${ }^{5}$ It is also noted, that there were 2 incidents where patients were asked to withdraw from the medication due to the occurrence of unfortunate complications. One of the patient's conditions worsened, where the ulcers enlarged from $5 \mathrm{~mm}$ to $10 \mathrm{~mm}$, causing disturbing pain and inability to eat properly. It is suspected that the Propolis cream was unable to contribute to the healing of RAS because the patient's bodily function was already deteriorating due to the discontinuation of multi-vitamin tablets that she had consumed daily. The second patient was reported having allergic reactions on the RAS lesions after applying Propolis $\AA$ cream of $1.0 \%$ on the second day, which is in accordance with the finding gained from previous studies where a higher level of concentration would cause an increase rate of skin irritation.

The data from Table 5 where two patients who applied the cream and succumbed to complications were put into data collection, were found to be insignificant as the p-value is less than 0.05 . Hence, we can conclude that Propolis ${ }^{\circledR}$ cream at $1 \%$ is still effective for the healing of RAS. By comparing the 2 creams of different 
concentration, from Table 6, we can conclude that there is no significant differences between them as the $\mathrm{p}$-value is larger than 0.05 .

The greatest limitation of this study was the small sample size. From the t-test for equality of means, where $0.140>0.05$, we can conclude that the difference is not significant between subjects that were given Propolis $₫$ cream at $0.5 \%$ concentration compared with subject given with $1.0 \%$ concentration of Propolis ${ }^{\circledR}$ cream. This can be overcome with an increase in the number of subjects, which then would provide a larger amount of data to be analyzed. A larger sample size may allow for more rigorous discrimination between the effects of Propolis $₫$ of concentration at $0.5 \%$ and $1.0 \%$.

Based on the results in this study, we advocate the usage of Propolis $\AA$ for patients with RAS who do not respond to other forms of treatment. We hope that a larger scale study will allow for Propolis $₫$ to become a first line therapy for all patients with RAS.

\section{CONCLUSION}

Propolis at $0.5 \%$ is more effective compared to $1.0 \%$ for the healing period of Recurrent Aphthous Stomatitis. This is due to the irritation caused by the higher level of concentration of
Propolis $®(1.0 \%)$, thus preventing a faster healing rate, consequently a longer healing period.

\section{REFERENCES}

1. Simone FM and S. Marla. Propolis and bee health: the natural history and significance of resin use by honey bees. Apidologie. May-June 2010;41(3):295-311.

2. Viuda MM, YR Navajas, JFA L'Opez and JAP Alvarez. 2008. Functional properties of honey, propolis, and royal jelly. J of Food Science. 2008;73(9):

3. Lotufo MA, CAL Júnior, MT Shimizu, C Renata, $G B$ Esther. Clinical evaluation of the topical use of Propolis in the Recurrent minor Aphthous ulceration. Cienc Odontol Bras. 2005;8(3):6-9.

4. Samet N, C Laurent, SM Susarla and RN Samet. The effect of bee propolis on recurrent aphthous stomatitis: a pilot study. Clin Oral Invest. Jun 2007;11(2):143-7.

5. Holcová S, H Marie. Efficacy and tolerability of propolis special extract GH 2002 as a lip balm against herpes labialis: a randomized, double-blind three-arm dose finding study. Doi:10.4236/Health. 2011;3(1): 49-55.

6. Bruch JM, Nathaniel ST. Clinical Oral Medicine and Pathology. United States, New York. Humana Press. 2011:53- 6. 